\title{
Cross-sectional study of seropositivity, lung lesions and associated risk factors of the main pathogens of Porcine Respiratory Diseases Complex (PRDC) in Goiás, Brazil
}

José Vanderlei Burim Galdeano ${ }^{1,2}$, Thaís Gasparini Baraldi', Maria Eugênia Silveira Ferraz'1, Henrique Meiroz de Souza Almeida ${ }^{1}$, Marina Lopes Mechler-Dreibi ${ }^{1}$, Willian Marcos Teixeira Costa ${ }^{3}$, Hélio José Montassier ${ }^{1}$, Luis Antonio Mathias ${ }^{1}$ and Luís Guilherme de Oliveira ${ }^{1 *}$ (D)

\begin{abstract}
Background: The objective of the study was to evaluate the occurrence and severity of Porcine Respiratory Diseases Complex (PRDC) pathogens in the Goiás State, Brazil. Were assessed the serological antibodies occurrency of Mycoplasma hyopneumoniae, Actinobacillus pleuropneumoniae and swine influenza virus (SIV), as well as the evaluation of pulmonary Mycoplasma-like lung lesions, pleuritis, histopathological lesions and diseases occurrence associated with risk factors, such as management, housing and productive indexes. We conveniently selected 2536 animals for serology testing, and 900 lungs at slaughtering of animals from 30 multisite herds in Goiás State, Brazil.

Results: For M. hyopneumoniae, all herds presented seropositive animals at some stage of production. Even though most herds (29/30) vaccinated against this pathogen, 90.0\% (27/30) of the herds presented at least 50.0\% of seropositive animals in finishing and slaughter. Overall, antibodies against A. pleuropneumoniae were present in lower occurrence, varying from $22.4 \%$ of the animals in the nursery phase to $1.3 \%$ of the animals at slaughter. Conversely, SIV circulated in most herds, with 29 seropositive herds without vaccination. The occurrence of anti-SIV antibodies was higher at slaughter (74.5\% of the animals) than nursery (41.8\% of the animals), and at slaughter, 23 herds (76.7\%) presented at least $50.0 \%$ of seropositive animals. All herds presented animals with pulmonary Mycoplasma-like lung lesions, and of the 900 lungs evaluated in the slaughterhouse, 665 (73.9\%) presented an average Mycoplasma-like lung lesions of 7.3\%. Evaluations of the pneumonia index (PI) showed that $73.3 \%$ of the herds were strongly affected by a pathology that manifested itself in different presentation forms. Microscopically, there was a predominance of bronchopneumonia lesions (74.6\% of affected lungs), with a high occurrence of the chronic form (57.1\%), and there was a moderate to marked proliferation of bronchial associated lymphoid tissue (BALT) in $64.1 \%$ of the affected lungs. Pleuritis were observed in $13.5 \%$ of the animals.
\end{abstract}

Conclusion: Serological tests evidenced that antibodies against App and SIV were present in the Goiás State herds, and high occurrence of $M$. hyopneumoniae antibodies in finishing phases and slaughter may be influenced by pathogen circulation in vaccinated herds, leading to respiratory lesions at slaughter. Additionally, swine influenza virus was broadly disseminated in technified herds in Goiás State.

Keywords: Mycoplasma-like lung lesion, Pneumonia, PRDC, Pleuritis, Serology, Swine

\footnotetext{
* Correspondence: luis.guilherme@unesp.br

${ }^{1}$ School of Agricultural and Veterinarian Sciences, São Paulo State University

(UNESP), Jaboticabal, SP, Brazil

Full list of author information is available at the end of the article
}

(c) The Author(s). 2019 Open Access This article is distributed under the terms of the Creative Commons Attribution 4.0 International License (http://creativecommons.org/licenses/by/4.0/), which permits unrestricted use, distribution, and

reproduction in any medium, provided you give appropriate credit to the original author(s) and the source, provide a link to the Creative Commons license, and indicate if changes were made. The Creative Commons Public Domain Dedication waiver (http://creativecommons.org/publicdomain/zero/1.0/) applies to the data made available in this article, unless otherwise stated. 


\section{Background}

The Porcine Respiratory Disease Complex (PRDC) is still one of the most challenging health issues faced by the pig industry worldwide due to the interaction of viral and bacterial infectious pathogens, environmental conditions and management practices [1]. Several bacterial and viral pathogens are involved in respiratory diseases in pigs. Mycoplasma hyopneumoniae (M. hyopneumoniae) and Actinobacillus pleuropneumoniae (App) are considered the most important primary bacterial pathogens associated with pulmonary lesions [2], and swine influenza virus (SIV) is the most important primary viral pathogen in Brazil followed by porcine circovirus type 2 (PCV2), since porcine reproductive and respiratory syndrome virus (PRRSV) has never been reported [3].

In Brazil, the infections caused by M. hyopneumoniae are considered a primary cause of respiratory problems [4]. Bacteriological, histopathological and immunohistochemical tests on lung samples showed that $97.2 \%$ of pneumonia lesions were caused by $M$. hyopneumoniae and Pasteurella multocida co-infection, highlighting the importance of those pathogens interaction for swine respiratory disease [5]. The presence of pulmonary consolidations, although not pathognomonic of M. hyopneumoniae infections [1], is positively associated with seropositive herds. The characteristic lesions of pneumonia, lymphadenomegaly and pulmonary congestion are strongly related to positive PCR results for $M$. hyopneumoniae and Pasteurella multocida [6].

In different countries, respiratory lesions are the main reason for lung condemnation as well as a lower slaughter line pace that is attributed to the higher percentage of carcasses that need to be trimmed [7] and are responsible for approximately $50.0 \%$ of the rejections in this species [8]. Thus, the objective of this study was to evaluate the occurrence and severity of respiratory diseases in multisite swine herds in the state of Goiás, in Brazil, by studying the presence of antibodies against $M$. hyopneumoniae, App and SIV in different production phases. We also evaluated Mycoplasma-like lung lesions, pleuritis, histopathological lesions and diseases occurrence associated with risk factors, such as management, housing and productive indexes.

\section{Methods}

\section{Study design}

This study was conducted in 2016 and 2017. We selected by convenience 30 production units with multisite farrow-to-finish herds. Goiás State contains approximately 100.000 sows, and the herds sampled represent $51.0 \%$ of Goiás production. Out of the 30 herds, 24 contained nursery and breeding sites at the same farm. In the other six herds, the nursery was located in the same farms as the finishing animals. The average herd size of sampled units ranged from 400 to 4000 sows. Briefly, five herds had between 400 and 1000 sows, 12 herds had between 1001 and 2000 sows, and 13 herds had sow herd between 2001 and 4000 sows.

The number of animals to be sampled in each class of production site (nursery, growing, finishing and slaughter) was determined using the following formula [9].

$$
N=\left[1-(1-C)^{\frac{1}{(D \times S)}}\right] \times\left[\frac{M-(D \times S-1)}{2}\right]
$$

in which:

$\mathrm{N}=$ required number of samples or animals to be investigated;

$\mathrm{C}=$ degree of confidence of the sampling procedure;

$\mathrm{D}=$ number of units with disease/infection (estimated prevalence);

$\mathrm{S}=$ sensitivity of the diagnostic test;

$\mathrm{M}=$ number of units (animals) of the herd to be studied.

The expected occurrence of pneumonia in each of the classes $(11 \%$ for nursery and growing phases, $35 \%$ for finishing phase) was based on studies previously conducted in the southern region of Brazil [10-12]. By using the formula, we considered the lowest diagnostic sensitivity (S) among the ELISA tests (IDEXX, Westbrook, ME, USA) to be $85 \%$ and the degree of confidence to be 95\% [13-15]. Thus, the number of needed study animals (M) from the total population of the 30 herds was 15 nursery animals, 30 growing animals, 10 finishing animals and 30 slaughter age animals, totaling 85 animals per farm. Considering this was a cross-sectional study, blood samples of the farm animals were collected on the same day, and the slaughterhouse animals were collected a few days later.

Blood was collected by jugular vein puncture using disposable sterile needles and syringes, deposited in commercial tubes (BD Franklin Lakes, New Jersey, USA) with clot activator, and centrifuged at $1500 \mathrm{x} g$ for $10 \mathrm{~min}$. The sera were separated, aliquoted and stored at $-20^{\circ} \mathrm{C}$ until analysis. In order to standardize the age of the animal samples, the nursery pigs were sampled at 50 days-age, the growing pigs at 94 days-age, the finishing pigs at 130 days-age, and the slaughter pigs were sampled between 150 and 180 days-age. Vaccination scheme of all herds sampled is presented in Table 1. For ethical reasons, the name of each vaccine was changed for letters.

In another approach, the slaughtering of the pigs from all previously sampled herds was monitored, and at least 30 animals were selected from each farm as commonly practiced in Brazil [16]. In the slaughterhouses, blood samples were collected at the time of bleeding, and the respective lungs of each pig was evaluated and classified 
Table 1 Vaccination procedures adopted by each of the 30 herds sampled, followed by the timing of vaccine use, in the state of Goiás, Brazil (2016/ 2017)

\begin{tabular}{|c|c|c|c|}
\hline Farm ID & M. hyopneumoniae & App & SIV \\
\hline 1 & Vaccine $A-7 d, 21 d^{*}$ & Vaccine $D-21 d, 35 d^{*}$ & None \\
\hline 2 & None & None & None \\
\hline 3 & Vaccine $B-21 d^{*}$ & Vaccine $E-30 d, 50 d^{*}$ & None \\
\hline 4 & Vaccine $B-21 d^{*}$ & Vaccine $E$ - 30d, 50d* & None \\
\hline 5 & Vaccine $B-21 d^{*}$ & Vaccine $E$ - 30d, 50d* & None \\
\hline 6 & Vaccine $A-15 d, 35 d^{*}$ & None & None \\
\hline 7 & Vaccine $C-35 d^{*}$ & Vaccine $F-18 d, 39 d^{*}$ & None \\
\hline 8 & Vaccine $A-7 d, 21 d^{*}$ & None & None \\
\hline 9 & Vaccine $A-21 d^{*}$ & None & None \\
\hline 10 to 30 & Vaccine $C-18 d^{*}$ & Vaccine $F-18 d, 39 d^{*}$ & None \\
\hline
\end{tabular}

${ }^{*} d$ (days) - age of piglet at vaccination

according to the pneumonia index (PI). Mycoplasmalike lung lesions score was evaluated by the same person that no access to any epidemiological data of the herds. Lesion grading was evaluated according to the total area of pneumonia, using the mean of each lobe score in relation to the total lung area $[16,17]$. Herds with average PI of up to 0.55 were considered free of pneumonia (Grade 0). Herds with average indexes between 0.56 and 0.89 obtained an intermediate classification (Grade 1), in which the presence of pneumonia occurred but did not characterize a threat to the herd. Herds with indexes above 0.90 were considered very affected, with severe occurrences of pneumonia in the herd (Grade 2) [16]. Regarding pleuritis, the lungs were evaluated for the presence or absence of lesions.

The mediastinic lymph nodes and lungs presenting Mycoplasma-like lung lesions in the pulmonary parenchyma were selected and collected for histopathological evaluation. For microscopic analysis, all tissue samples were fixed by immersion in formalin for $72 \mathrm{~h}$, transferred to $70 \%$ alcohol, and then embedded in paraffin. Samples of tissues were cut and stained with hematoxylin/eosin (HE) in the CEDISA Laboratory (Center for Diagnosis of Animal Health, Concordia, Brazil).

A total of 2536 blood serum samples collected from herds and slaughterhouses were tested for the detection of specific antibodies against M. hyopneumoniae, App and SIV by the Enzyme Linked Immunosorbent Assay ELISA with the commercial kits IDEXX (Westbrook, ME, USA) M. hyo. Ab Test, IDEXX APP-ApxIV Ab Test, and IDEXX Influenza A Ab test, respectively, according to manufacturer's instructions. The relative level of antibody in the sample was determined by calculating the sample to positive $(\mathrm{S} / \mathrm{P})$ ratio, and the cut-off values for M. hyopneumoniae, App and SIV were 0.40, 0.50, and 0.40 , respectively.

\section{Epidemiologic data collection}

In every sampled farm, an epidemiologic questionnaire with 114 questions was used to collect data regarding: zootechnical indexes, management practices, application of biosecurity measures, which vaccines were used, the structure of animals facilities, adoption of welfare practices, environmental data and the feeding system used in the farm. Categorical data was obtained through dichotomous questions, which only allowed yes or no as an answer. Continuous data (mostly zootechnical indexes) were obtained by questions which allowed any type of numeric answer, The questionnaire information was filled by authors during an interview with farm owner and technical team. The interviewer was trained in order to not influence the farmer and the technical team answers. The variables are described in Additional file 1.

\section{Data analysis}

\section{Serological results}

All values of frequencies obtained for each strata (age group) had a 95\% confidence interval (CI) calculated using Wilson's methodology.

\section{Epidemiologic data}

The categorical data obtained from the 30 sampled herds was further tabulated. The outcomes selected to analyze the explanatory variables were the serology results of each strata and the PI of the herds.

In order to investigate potential association between the outcomes and categorical explanatory variables, the Fisher's Exact Test $(p<0.2)$ was used. All potential significant associations were then used in univariate logistic regression models $(p<0.05)$ to assess the association and to obtain the OR value and its $95 \%$ confidence interval (CI). For this analysis two explanatory variables were transformed into categorical data, regarding stocking density at weaning, more than $0.3 \mathrm{~m}^{2} /$ animal was attributed value 1 , while less than $0.3 \mathrm{~m}^{2} /$ animal was given the value 0 ; regarding stocking density at growing and finishing, more than $1 \mathrm{~m}^{2} /$ animal was given the value 1 and less than $1 \mathrm{~m}^{2} /$ animal was given the value 0 . Another converted variable was the number of animals per trough at weaning, growing and finishing phase, more than 35 animalstrough was given the value 1 and less than 35 animalstrough was given the value 0 . The data analysis was performed using Epi Info ${ }^{\text {tw }}$ (Centers for Disease Control and Prevention, Atlanta, USA).

Association continuous variables investigated as potential risk factors and the serological data obtained (outcome), were detected by simple linear regression models were performed $(p<0.05)$ using the software $\mathrm{R}[18]$. Whenever significant associations were found, the residuals were analyzed to verify whether the statistical assumptions of the simple linear regression were met. In 
cases in which the assumptions were not met, the association was investigated using Spearman's coefficient $(p<$ 0.05) calculation for non-parametric data.

\section{Results}

Serology

The serological results for the three infectious pathogens per class and the respective 95\% CI are shown in Additional files 2, 3 and 4. Regarding M. hyopneumoniae, we were not able to differ vaccine antibodies from infection, which does limit the interpretation of the data. The serological data indicated that SIV probably circulated in most of the herds at all stages of production, with a higher proportion of positive samples at the later stages. Likewise, the data observed for App had a particular characteristic. Disregarding the detection of maternal antibodies in nursery, a low occurrence was observed in subsequent phases, which may indicate pathogen circulation in the herds (Table 2).

\section{Serology for mycoplasma hyopneumoniae}

Regarding M. hyopneumoniae, all herds presented seropositive pigs at some stage of production, but most of the herds were vaccinated against $M$. hyopneumoniae, excluding farm 2, which was certified free of $M$. hyopneumoniae without vaccination. Regarding the nursery piglets, 11 herds presented seronegative animals (2, 9, $11,12,16,17,20,22,23,25$ and 30) (Table 2). Four of them presented seronegative animals during growing phase, and seropositive animals in the finishing phase (2, 12, 25 and 30), while the other seven herds presented seropositive animals in the growing and finishing phases $(9,11,16,17,20,22$ and 23) (Table 2). At slaughter, only farm 2 showed seronegative animals. This farm presented $10.0 \%$ of seropositive animals in the finishing phase, being negative in all other previous phases and at slaughter. Only five herds (1, 3, 5, 6 and 8) presented more than $50.0 \%$ of seropositive pigs in both the nursery and growing phases. At finishing phase, 17 herds presented more than $50.0 \%$ of seropositive pigs (Table 2). At slaughter, 27 herds presented more than $50.0 \%$ of seropositive pigs, with 23 herds presenting more than $90.0 \%$.

\section{Serology for APP}

Regarding App, 25 herds were seropositive in at least one of the production phases, and only five were seronegative in all of them $(2,3,5,6,11)$. Considering that most of the herds were vaccinated in the nursery phase (excluding herds 2, 6, 8 and 9), we observed only 22 herds with seropositive animals in this phase. In the growing phase, only four herds were positive, and one of them was negative in the nursery phase. Five herds presented seropositive pigs at the finishing phase, and at slaughter, 14. Farm 1 presented seropositive animals at all stages of production.

Only three herds had more than $50.0 \%$ of seropositive animals in the nursery phase $(9,18$ and 22) (Table 2). The occurrences varied from $22.4 \%$ in the nursery phase to $1.3 \%$ in the growing phase. This low occurrence was also observed at slaughter.

\section{Serology for SIV}

Regarding the serology for SIV, Farm 9 was the only seronegative. The number of seropositive animals was high in the later production phases in eight herds $(2,4,5,9,11$, 20, 26 and 28) (Table 2) and low in five herds (1, 2, 4, 8 and 28). Farm 5 presented seropositive animals only at slaughter. Since vaccination against SIV was not practiced, the number of seropositive animals from nursery to slaughter ranged from 41.8 to $74.5 \%$. At slaughter, 24 herds had at least $50 \%$ seropositive animals for SIV.

\section{Pulmonary evaluation at slaughter}

All herds presented animals with Mycoplasma-like lung lesions at slaughter. In individual evaluations, 24.4\% (220/ 900 ) of the animals presented lung lesion score higher than $10 \%$. In general, the mean percentages of lung lesions ranged from 0.2 to $17.4 \%$, with an average of $7.3 \%$. All herds contained animals with Mycoplasma-like lung lesions, including Farm 2 (Table 3).

For the pneumonia index, only one farm was classified as grade 0 , six as grade 1 , and 23 as grade 2 , the highest score in this scoring system. The herds with the worst score represented $76.7 \%$ of the herds (Table 3). With regard to pleuritis, 29 herds had at least one affected animal, with occurrences varying from 3.3 to $50.0 \%$ and an average of $10.3 \%$ (Table 3 ). The farm with the highest percentage of pleuritis (farm 18) was negative for ApxIV in the growing and finishing stages and presented antibodies against the toxin at slaughter. The occurrence of animals with Mycoplasma-like lung lesions ranged from 6.7 to $96.7 \%$, with a mean of $80.3 \%$. In addition, we observed eight lungs with abscess injuries at slaughter.

\section{Histopathology}

One lung lesion fragment was collected per pig at slaughter. In total, 665 fragments were analyzed and 15 different pathological pictures were observed (Table 4). There was a predominance of bronchopneumonia $(74.6 \%$; 496/665), with the chronic form being the most prevalent $(57.1 \% .380 / 665)$. In relation to pleuritis, the occurrence was 13.5\% (90/665). Regarding bronchial associated lymphoid tissue (BALT), there were $63.8 \%$ of pathological findings $(424 / 665)$, most of which were considered to be marked to moderate (64.2\%; 272/665). 
Table 2 Percentage of seropositivity of M. hyopneumoniae, App and SIV antibodies in the pigs in the nursery, growing, and finishing phases and at slaughter from the 30 sampled herds in the State of Goiás, Brazil (2016/2017). S/P cut-off values for M. hyopneumoniae, App and SIV were 0.4, 0.5, and 0.4, respectively

\begin{tabular}{|c|c|c|c|c|c|c|c|c|c|c|c|c|}
\hline \multicolumn{13}{|c|}{ Seropositivity } \\
\hline \multirow[t]{2}{*}{ Herd ID } & \multicolumn{3}{|c|}{ Nursery $\left(50 d^{a}\right)$} & \multicolumn{3}{|c|}{ Growing (94d) } & \multicolumn{3}{|c|}{ Finishing (130d) } & \multicolumn{3}{|c|}{ Slaughter (150-180d) } \\
\hline & Mhyo & App & SIV & Mhyo & App & SIV & Mhyo & App & SIV & Mhyo & App & SIV \\
\hline 1 & 66.7 & 13.3 & 66.7 & 86.7 & 10.0 & 6.7 & 100.0 & 10.0 & 0.0 & 100.0 & 5.0 & 0.0 \\
\hline 2 & 0.0 & 0.0 & 13.3 & 0.0 & 0.0 & 57.1 & 10.0 & 0.0 & 0.0 & 0.0 & 0.0 & 3.3 \\
\hline 3 & 78.6 & 0.0 & 92.9 & 83.3 & 0.0 & 83.3 & 93.3 & 0.0 & 100.0 & 93.3 & 0.0 & 100.0 \\
\hline 4 & 40.0 & 0.0 & 86.7 & 46.7 & 25 & 63.3 & 100.0 & 0.0 & 60.0 & 93.3 & 3.3 & 30.0 \\
\hline 5 & 80.0 & 0.0 & 0.0 & 63.3 & 0.0 & 0.0 & 10.0 & 0.0 & 0.0 & 73.3 & 0.0 & 3.3 \\
\hline 6 & 93.3 & 0.0 & 66.7 & 66.7 & 0.0 & 100.0 & 90.0 & 0.0 & 50.0 & 93.3 & 0.0 & 96.7 \\
\hline 7 & 20.0 & 26.7 & 60.0 & 10.0 & 0.0 & 96.7 & 20.0 & 0.0 & 100.0 & 100.0 & 10.0 & 96.7 \\
\hline 8 & 100.0 & 28.6 & 92.9 & 96.3 & 0.0 & 22.2 & 100.0 & 0.0 & 40.0 & 46.7 & 0.0 & 76.7 \\
\hline 9 & 0.0 & 69.2 & 0.0 & 18.5 & 0.0 & 0.0 & 100.0 & 0.0 & 0.0 & 80.0 & 6.7 & 0.0 \\
\hline 10 & 6.7 & 25.0 & 46.7 & 10.0 & 5.0 & 70.0 & 70.0 & 4.6 & 30.0 & 93.3 & 0.0 & 100.0 \\
\hline 11 & 0.0 & 0.0 & 13.3 & 20.0 & 0.0 & 86.7 & 50.0 & 0.0 & 45.5 & 100.0 & 0.0 & 46.7 \\
\hline 12 & 0.0 & 6.7 & 57.1 & 0.0 & 0.0 & 40.0 & 90.0 & 10.0 & 100.0 & 100.0 & 0.0 & 100.0 \\
\hline 13 & 6.7 & 13.3 & 73.3 & 26.7 & 0.0 & 56.7 & 70.0 & 0.0 & 100.0 & 100.0 & 0.0 & 100.0 \\
\hline 14 & 6.3 & 0.0 & 26.7 & 3.3 & 0.0 & 90.0 & 40.0 & 0.0 & 70.0 & 43.3 & 6.67 & 76.7 \\
\hline 15 & 13.3 & 20.0 & 40.0 & 13.3 & 0.0 & 96.7 & 30.0 & 10.0 & 80.0 & 93.1 & 10.0 & 93.3 \\
\hline 16 & 0.0 & 20.0 & 13.3 & 16.7 & 0.0 & 100.0 & 20.0 & 0.0 & 100.0 & 96.7 & 0.0 & 93.3 \\
\hline 17 & 0.0 & 13.3 & 40.0 & 10.0 & 0.0 & 100.0 & 100.0 & 0.0 & 100.0 & 100.0 & 0.0 & 93.3 \\
\hline 18 & 40.0 & 80.0 & 13.3 & 3.3 & 0.0 & 93.3 & 30.0 & 0.0 & 100.0 & 100.0 & 3.3 & 100.0 \\
\hline 19 & 6.7 & 0.0 & 46.7 & 20.0 & 0.0 & 86.7 & 70.0 & 0.0 & 60.0 & 100.0 & 6.7 & 80.0 \\
\hline 20 & 0.0 & 6.7 & 13.3 & 3.3 & 0.0 & 6.7 & 20.0 & 0.0 & 50.0 & 86.7 & 43.3 & 78.6 \\
\hline 21 & 46.7 & 20.0 & 13.3 & 16.7 & 0.0 & 3.3 & 20.0 & 0.0 & 100.0 & 83.3 & 0.0 & 83.3 \\
\hline 22 & 0.0 & 60.0 & 20.0 & 3.3 & 0.0 & 100.0 & 60.0 & 0.0 & 100.0 & 96.7 & 10.0 & 96.7 \\
\hline 23 & 0.0 & 46.7 & 53.3 & 16.7 & 0.0 & 96.7 & 100.0 & 0.0 & 100.0 & 100.0 & 0.0 & 100.0 \\
\hline 24 & 26.7 & 13.3 & 66.7 & 23.3 & 0.0 & 96.7 & 100.0 & 0.0 & 100.0 & 100.0 & 0.0 & 100.0 \\
\hline 25 & 0.0 & 6.7 & 33.3 & 0.0 & 0.0 & 100.0 & 10.0 & 10.0 & 50.0 & 100.0 & 16.7 & 96.7 \\
\hline 26 & 6.7 & 33.3 & 26.7 & 10.0 & 3.3 & 96.7 & 100.0 & 0.0 & 100.0 & 100.0 & 20.0 & 66.7 \\
\hline 27 & 13.3 & 18.8 & 46.7 & 3.3 & 0.0 & 100.0 & 40.0 & 0.0 & 60.0 & 100.0 & 13.3 & 83.3 \\
\hline 28 & 20.0 & 26.7 & 26.7 & 16.7 & 0.0 & 100.0 & 47.4 & 0.0 & 10.0 & 100.0 & 0.0 & 3.3 \\
\hline 29 & 6.7 & 33.3 & 60.0 & 40.0 & 0.0 & 86.7 & 10.0 & 0.0 & 80.0 & 100.0 & 10.0 & 100.0 \\
\hline 30 & 0.0 & 40.0 & 46.7 & 0.0 & 3.3 & 46.7 & 100.0 & 0.0 & 100.0 & 100.0 & 0.0 & 83.3 \\
\hline$x$ & 22.4 & 20.5 & 41.8 & 24.2 & 1.3 & 69.8 & 61.7 & 1.6 & 66.1 & 88.4 & 5.7 & 74.5 \\
\hline
\end{tabular}

${ }^{a}$ Mhyo Mycoplasma hyopneumoniae, App Actinobacillus pleuropneumoniae, SIV Swine influenza virus. $d$ days; age of pigs

\section{Risk factor association}

The logistic regression of the categorical variables showed potential associations between the investigated variables and the occurrence of APP, M. hyopneumoniae and SIV. APP seropositivity at slaughter was positively associated with more than 30 pigs per through (OR: 12.24; 95\%CI 1.27-118.35), while using protocols of empty period between batches in the growing-finishing pig facilities was labeled as a protective factor (OR: 0.10; 95\%CI 0.02-0.66).
The variable "Cross-fostering" in the maternity facilities, which aimed at redistributing pigs to standardize the size of the litters, was inversely associated with the SIV seropositivity in the growing-finishing pigs (OR: 0.92; 95\% CI 0.85-0.99). The OR and $p$ values of all associations are shown in Table 5. A logistic regression model was attempted including all variables with significant association in the univariate analysis; however, no significant results were obtained. 
Table 3 Results of the pulmonary evaluations of 900 pigs at slaughter related to the percentage of Mycoplasma-like lung lesions areas and pleuritis, as well as the classification of the herds evaluated for PI. The animals were from commercial herds in the state of Goiás, Brazil (2016/2017)

\begin{tabular}{|c|c|c|c|c|c|}
\hline Farm & $\begin{array}{l}\% \text { of average } \\
\text { lung lesion score }\end{array}$ & $\mathrm{Pl}$ & $\begin{array}{l}\text { Classification of } \\
\text { the herd by } \mathrm{Pl}^{\mathrm{a}}\end{array}$ & $\%$ of pleuritis & $\begin{array}{l}\% \text { of animals with } \\
\text { lung lesions }\end{array}$ \\
\hline 01 & 7.9 & 1.13 & 2 & 10.0 & 86.7 \\
\hline 02 & 0.2 & 0.07 & 0 & 0.0 & 6.7 \\
\hline 03 & 5.8 & 1.0 & 2 & 6.7 & 86.7 \\
\hline 04 & 5.0 & 0.80 & 1 & 6.7 & 56.7 \\
\hline 05 & 4.0 & 0.83 & 1 & 3.3 & 73.3 \\
\hline 06 & 6.6 & 1.10 & 2 & 10.0 & 80.0 \\
\hline 07 & 11.4 & 1.50 & 2 & 10.0 & 90.0 \\
\hline 08 & 14.5 & 1.87 & 2 & 13.3 & 96.7 \\
\hline 09 & 3.3 & 0.73 & 1 & 13.3 & 70.0 \\
\hline 10 & 3.9 & 0.90 & 2 & 13.3 & 76.7 \\
\hline 11 & 3.7 & 0.87 & 1 & 13.3 & 80.0 \\
\hline 12 & 7.2 & 1.17 & 2 & 23.3 & 83.3 \\
\hline 13 & 9.7 & 1.43 & 2 & 10.0 & 93.3 \\
\hline 14 & 3.8 & 0.87 & 1 & 3.3 & 73.3 \\
\hline 15 & 5.7 & 1.03 & 2 & 6.7 & 86.7 \\
\hline 16 & 7.5 & 1.23 & 2 & 6.7 & 86.7 \\
\hline 17 & 6.0 & 1.03 & 2 & 3.3 & 80.0 \\
\hline 18 & 7.5 & 1.10 & 2 & 50.0 & 80.0 \\
\hline 19 & 12.0 & 1.72 & 2 & 6.7 & 96.7 \\
\hline 20 & 7.5 & 1.20 & 2 & 10.0 & 86.7 \\
\hline 21 & 7.5 & 1.30 & 2 & 6.7 & 83.3 \\
\hline 22 & 6.6 & 1.10 & 2 & 6.7 & 73.3 \\
\hline 23 & 3.7 & 0.90 & 2 & 6.7 & 80.0 \\
\hline 24 & 17.4 & 2.03 & 2 & 13.3 & 96.7 \\
\hline 25 & 11.4 & 1.50 & 2 & 6.67 & 93.3 \\
\hline 26 & 9.3 & 1.40 & 2 & 13.3 & 93.3 \\
\hline 27 & 4.0 & 0.90 & 2 & 13.3 & 76.7 \\
\hline 28 & 14.9 & 1.93 & 2 & 13.3 & 96.7 \\
\hline 29 & 5.3 & 0.87 & 1 & 3.3 & 66.7 \\
\hline 30 & 5.6 & 0.97 & 2 & 6.7 & 80.0 \\
\hline Average & 7.3 & 1.15 & & 10.3 & 80.3 \\
\hline
\end{tabular}

*Herds with pneumonia indexes of up to 0.55 were considered free of pneumonia (Grade 0 ). Herds with indexes between 0.56 and 0.89 obtained an intermediate classification (Grade 1), in which the presence of pneumonia occurred but did not characterize a threat to the herd. Herds with indexes above 0.90 were considered with severe occurrences of pneumonia in the herds (Grade 2)

\section{Linear regression}

The continuous variables were submitted to a linear regression model in order to detect potential associations. Table 6 shows the $\mathrm{R}^{2}$ and $p$ values obtained for each model.

The presence of $M$. hyopneumoniae antibodies at weaning was also inversely associated with ADWG. At the growing-finishing phase, it was also inversely associated with the number of days of empty period between batches and the adoption of cleaning and disinfection protocols at the finishing-growing facilities (Table 7). A positive association was detected between the $M$. hyopneumoniae seropositivity and the presence of other nearby pig herds.

The SIV seropositivity in the growing/finishing phases was positively associated with mortality in the phase. Since the mortality in the finishing pigs also presented a positive association with higher PI and medium size pulmonary lesions, all aforementioned variables were used to create a multiple linear regression model $\left(R^{2}=0.43\right.$ 
Table 4 Characterization of the different histological lesions observed in 665 lungs of pigs from commercial herds located in the state of Goiás, Brazil affected by Mycoplasma-like lung lesions at slaughter (2016/2017)

\begin{tabular}{|c|c|}
\hline Histological features & $\begin{array}{l}\text { Percentage of affected } \\
\text { lung fragments }\end{array}$ \\
\hline Chronic bronchopneumonia $^{a}$ & $57.1 \%(380 / 665)$ \\
\hline Suppurative bronchopneumonia & $15.6 \%(104 / 665)$ \\
\hline Granulomatous bronchopneumonia & $0.3 \%(2 / 665)$ \\
\hline Fibrinous bronchopneumonia $^{a}$ & $0.2 \%(1 / 665)$ \\
\hline Subacute bronchopneumonia & $0.3 \%(2 / 665)$ \\
\hline Catarrhal bronchopneumonia ${ }^{a}$ & $1.1 \%(7 / 665)$ \\
\hline Chronic bronchiolitis $^{a}$ & $3.3 \%(22 / 665)$ \\
\hline Necrotic bronchiolitis ${ }^{a}$ & $10.5 \%(07 / 665)$ \\
\hline Chronic pleuritis $^{\mathrm{a}}$ & $13.1 \%(87 / 665)$ \\
\hline Fibrinous pleuritis & $0.5 \%(3 / 665)$ \\
\hline Pulmonary abscess & $0.1 \%(1 / 665)$ \\
\hline Interstitial pneumonia & $3.6 \%(24 / 665)$ \\
\hline Bronchointerstitial pneumonia ${ }^{a}$ & $4.5 \%(30 / 665)$ \\
\hline Granulomatous pneumonia & $0.3 \%(2 / 665)$ \\
\hline Chronic pneumonia ${ }^{a}$ & $0.3 \%(2 / 665)$ \\
\hline $\begin{array}{l}\text { Bronchial associated lymphoid } \\
\text { tissue (BALT) }\end{array}$ & $\begin{array}{l}\text { Percentage of affected } \\
\text { lungs }\end{array}$ \\
\hline Absence of hyperplasia & $36.2 \%(241 / 665)$ \\
\hline Mild hyperplasia & $27.1 \%(115 / 424)$ \\
\hline Discrete hyperplasia & $8.7 \%(37 / 424)$ \\
\hline Moderate hyperplasia & $35.4 \%(150 / 424)$ \\
\hline Total & $63.8 \%(424 / 665)$ \\
\hline
\end{tabular}

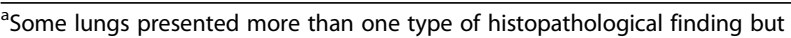
were classified according to the most extensive/predominant lesion

and $p<0.05$ ). Despite the relatively low $\mathrm{R}^{2}$, the model was significant, indicating a potential association between the variables.

Both PI and average pulmonary lesion size presented a positive and significant association with the M. hyopneumoniae seropositivity in the finishers when using the Spearman correlation coefficient (Table 7). Regarding App, an inverse correlation was observed between the seropositivity in the growing phase and the use of well- conserved barn curtains, and between the herd seropositivity and the use of "all-in/all-out" in the farrowing facilities.

\section{Discussion}

A high seropositivity of $M$. hyopneumoniae antibodies was found at the finishing phase and slaughter (61.7 and $88.4 \%$ of the animals, respectively), although 13 herds had less than $50.0 \%$ of seropositive animals in finishing and at slaughter phases. Lower occurrence of antibodies were observed in nursery and growing animals (22.4 and $24.2 \%$, respectively).

Taking into account the presence of Mycoplasma-like lung lesions at slaughter and the high occurrence of seropositive animals in finishing phases, it is possible to infer that vaccination was not preventing pathogen circulation in later phases in these herds. In addition, consequently, the high number of seropositive could have been be influenced by new infection. In an experimental study, Mycoplasma hyopneumoniae shedding did not show significant differences between vaccinated and non-vaccinated populations [19]. Thus, it is possible that pathogen circulation was still happening in finishing phases of the sampled herds, even though the majority of the herds were vaccinated for M. hyopneumoniae. However, since this study was cross-sectional and did not provide direct evidence of pathogen circulation, it is not possible to confirm that hypothesis.

The serological results for App showed a low occurrence of the ApxIV toxin antibodies, with the highest occurrence found in the nursery animals (20.5\%), followed by $5.7 \%$ at slaughter, and the lowest in the growing and finishing animals (1.3 and 1.6\%, respectively). Unlike the M. hyopneumoniae and SIV ELISA tests, the serological test used in this study did not detect vaccinal antibodies, and detected both pathogenic and non-pathogenic strains. The prevalence found in the nurseries may be explained by maternal derived antibodies, which are detectable until up to 12 weeks of age [20,21].

Despite the non-vaccination against SIV, a high seropositivity in herds was observed along all stages of production $(41.8 \%$ in the nursery phase, $69.8 \%$ in the growing phase, $66.1 \%$ in the finishing phase, and $74.5 \%$

Table $5 \mathrm{OR}$ and $p$-values of the associations found by univariate logistic regression between the investigated variables and the SIV, APP and M. hyopneumoniae seropositivity in the sampled herds

\begin{tabular}{lllll}
\hline Dependent variable & Independent variable & $P$ & $\mathrm{OR}$ & \multicolumn{1}{c}{$95 \% \mathrm{Cl}$} \\
\hline App weaning & Colostrum ingestion aid & 0.03 & 1.04 & 0.10 \\
App growing-finishing & $\begin{array}{l}\text { Empty period between batches in } \\
\text { maternity facilities }\end{array}$ & 0.02 & $1.00-1.09$ & $0.02-0.66$ \\
App slaughter & $\begin{array}{l}\text { More than 30 pigs per through in } \\
\text { growing-finishing phases } \\
\text { SIV growing-finishing }\end{array}$ & Cross-fostering & 0.03 & 0.92 \\
\hline
\end{tabular}


Table 6 Associations detected between the APP, SIV and M. hyopneumoniae seropositivity and the investigated variables using univariate linear regression models $(p<0.05)$

\begin{tabular}{|c|c|c|c|}
\hline Dependent variables & Independent variables & $R^{2}$ & $p$ \\
\hline Average daily weight gain (g/day) & M. hyopneumoniae seropositivity at weaning & 0.39 & $2.00 \mathrm{e}-04$ \\
\hline Average daily weight gain (g/day) & M. hyopneumoniae seropositivity at growing-finishing & 0.34 & 7.00 e- 04 \\
\hline Mortality in finishing phase (\%) & SIV seropositivity in growing-finishing & 0.38 & $2.00 \mathrm{e}-04$ \\
\hline Mortality in finishing phase (\%) & Average pulmonary lesion extension (\%) & 0.17 & 2.00 e- 02 \\
\hline Mortality in finishing phase (\%) & PI & 0.20 & 1.00 e-02 \\
\hline M. hyopneumoniae seropositivity in growing-finishing & Empty period between batches in growing-finishing facilities & 0.26 & 4.00 e-03 \\
\hline
\end{tabular}

at slaughter), a fact that was expected since enzootic SIV circulation in Brazilian herds has been reported [10]. Considering that the herds sampled corresponds to $51.0 \%$ of the Goiás State herd, the high seropositivity of SIV in non-vaccinated animals indicate that this pathogen is circulating in these herds, although there is no information about the strains. This result can be justified by animal production at multisite, since influenza $\mathrm{A}$ is usually introduced by animal transit [22].

To evaluate the degree of the occurrence of pneumonia in the herds, the PI of each farm was calculated. The mean value found among the 30 herds was 1.15 , ranging from 0.07 to 2.03 , confirming the presence of pneumonia in the herds. Considering this information, the state of Goiás appears to be in accordance with the prevalence data from other Brazilian states, with values varying from 0.86 to 1.54 and a mean of 1.03 [21]. Herds with PIs above 0.90 represent a serious occurrence of pneumonia, and the severity of the clinical status is proportional to the increase in the PI value [16]. The farm that presented the highest PI was also the one with the highest percentage of Mycoplasma-like lung lesions at slaughter (farm 24), with $96.7 \%$ (29/30) of the herd having this injury. In this farm, the percentage of seropositive animals for M. hyopneumoniae and SIV was higher in the latter phases than in the first ones, presenting
$100 \%$ of seropositive pigs at slaughter. It is evident that there are herd risk factors that favor the occurrence of pneumonia and, if uncorrected, may intensify losses, mainly due to the association with secondary pathogens [11].

This fact leads us to believe that the occurrence of pleuritis was strongly associated with other pathogens. As observed in studies in slaughterhouses, $33.3 \%$ of the rejected carcasses presented pleuritis lesions [23]. The only farm with a PI of 0 also had no pleuritis lesions at slaughter. Despite the major negative serological results for M. hyopneumoniae, the farm presented animals seropositive to SIV in the nursery and growing phases.

Most of the histological lesions observed in this study (74.6\%) were described as bronchopneumonia prevailing in the chronic form (57.1\%), with characteristics of BALT hyperplasia ranging from moderate to severe (64.2\%). These findings were suggestive, but not exclusive, of an $M$. hyopneumoniae infection since other respiratory pathogens may lead to similar lesions [24]. Other pathogens, such as SIV or P. multocida, should be considered within the most likely differential diagnoses [25]. The occurrence of high percentage of Mycoplasmalike lung lesions in the slaughterhouses suggests that vaccination protocols do not completely prevent this type of lesion, which reinforces the importance of management and biosecurity practices.

Table 7 Associations obtained between the Actinobacillus pleuropneumoniae, Mycoplasma hyopneumoniae and influenza seropositivities in the sampled herds from Goiás, Brazil, when using Spearman's coefficient test at ${ }^{*} p<0.05$

\begin{tabular}{|c|c|c|c|}
\hline Dependent variable & Independent variable & Coefficient & $p$ \\
\hline Average pulmonary lesion area & M. hyopneumoniae seropositivity at slaughter & 0.38 & 0.035 \\
\hline Pneumonia index (PI) & M. hyopneumoniae seropositivity at slaughter & 0.37 & 0.041 \\
\hline ApxIV seropositivity in growing animals & Well conserved barn curtains & -0.48 & 0.007 \\
\hline ApxIV herd level seropositivity & Performing "all-in/all-out" in the maternity facilities & -0.39 & 0.031 \\
\hline M. hyopneumoniae seropositivity in growing animals & Protocol for cleaning and disinfecting in growing/finishing phases & -0.39 & 0.034 \\
\hline M. hyopneumoniae seropositivity in growing animals & Performing "all-in/all-out" in the growing and finishing facilities & -0.46 & 0.011 \\
\hline M. hyopneumoniae seropositivity at slaughter & Other swine herds nearby & 0.40 & 0.028 \\
\hline SIV seropositivity in growing animals & Other swine herds nearby & 0.42 & 0.020 \\
\hline
\end{tabular}


The injuries characterized as interstitial pneumonia (8.1\%) bronchiolitis either chronic or necrotizing (4.4\%), are generally induced by viral infection. However, animals in remission may present pulmonary lesions similar to those caused by $M$. hyopneumoniae, and additional confirmatory tests, such as PCR, are required [26].

The microscopic observation of chronic and fibrinous pleuritis (13.5\%), the macroscopic observation of pleuritis (mean of $10.3 \%$ ), and the occurrence of eight individual lung samples with abscesses are compatible with App infection. These data corroborate a previous study [23] in which only $8.0 \%$ of the animals presented lesions characteristic of pleuritis. On the contrary, there was no correlation with the presence of pneumonia in other parts of the lung. Studies confirm that the type and severity of the lung lesions in slaughter pigs result from dynamic and complex interactions between multiple infectious pathogens, such as co-infection of M. hyopneumoniae and Pasteurella multocida, mainly associated with pneumonia, and co-infection of App and P. multocida, mainly associated with pleuritis [5].

Regarding APP, a positive association was discovered between anti-ApxIV antibodies and more than 30 animals per trough (OR: 12.24). App transmission can occur by the air or by direct contact, specifically nose-to-nose contact. A previous study showed that nose-to-nose transmission was up to 10 times more frequent than air transmission [27]. Higher number of animals at trough feeding may be a reflection of the high density of animals per pen, which increases the direct contact between animals, consequently facilitating App transmission.

Protective factors were also detected in this study (inverse associations), such as having protocols of empty period between batches in the facilities and the App seropositivity in growers (OR: 0.10 ). Not performing an empty period between batches was positively associated with pleuritis and APP seropositivity in the swine herds, reinforcing the idea that all-in/all-out management is an important procedure in the prevention of respiratory diseases [2].

The linear regression detected an inverse association between the number of days of empty period between batches and the occurrence of $M$. hyopneumoniae antibodies in the growers. This association could be explained by the production flow of the sampled herds since most of the herds were multisite and the arrival of susceptible animals from the maternity sites was constant.

A reduction in the daily weight gain is the main production impact caused by $M$. hyopneumoniae in the pork producing chain, corroborating the inverse association found in this study between the ADWG and $M$. hyopneumoniae antibodies found in the growers and finishers. A previous study showed that losses due to $M$. hyopneumoniae infection could reach
US\$2.80 for each infected animal with pulmonary lesions [28].

Regarding SIV, the adoption of cross-fostering practices improve colostrum ingestion, resulting in a more robust protection against infectious diseases [29].

\section{Conclusion}

This study showed that the seropositivity against $M$. hyopneumoniae, Actinobacillus pleuropneumoniae and SIV, and lung lesions suggest that PRDC could be a problem in the pig production systems in the state of Goiás. Thus, associated risk and protective factors were related with management, reinforcing the importance of good management practices for pig health.

\section{Supplementary information}

Supplementary information accompanies this paper at https://doi.org/10. 1186/s40813-019-0130-0.

Additional file 1. Description of the occurrence of the variables investigated as risk factors and their respective frequencies in the herds sampled in the state of Goiás, Brazil.

Additional file 2. Mycoplasma hyopneumoniae seroprevalence in the weaners, growers, finishers and pigs at slaughter from the 30 sampled herds from the state of Goiás, Brazil, and the respective 95\% confidence interval (Cl 95\%)

Additional file 3. Actinobacillus pleuropneumoniae seroprevalence in the weaners, growers, finishers and pigs at slaughter from the 30 sampled herds from the state of Goiás, Brazil, and the respective $95 \%$ confidence interval (Cl 95\%)

Additional file 4. SIV seroprevalence in the weaners, growers, finishers and pigs at slaughter from the 30 sampled herds from the state of Goiás, Brazil, and the respective 95\% confidence interval (Cl 95\%).

\section{Acknowledgements}

Not applicable.

\section{Author's contributions}

Study design: LGO, JVBG, WMTC, TGB. Sampling: JVBG. Laboratory analysis: TGB, HMSA, MESF, HJM. Data analysis: TGB, HMSA, MESF, LAM. Interpretation of data: JVBG, LGO, HMSA, MLMD, LAM, HJM. Writing the manuscript: JVBG, LGO, HMSA, MLMD, MESF. All authors read, reviewed, and approved the final manuscript.

\section{Funding}

This work was conducted with the financial support provided by CEVA Animal Health.

\section{Availability of data and materials}

Data sets used and analysed during the current study are available from the corresponding author upon reasonable request.

\section{Ethics approval and consent to participate}

This research was approved by the São Paulo State University (Unesp) animal experimentation ethics committee (CEUA). The approval certificate was registered under the protocol $3899 / 17$.

Consent for publication

Not applicable.

\section{Competing interests}

At the time of submission of this article, William Marcos Teixeira Costa is employed by CEVA Animal Health, in Brazil, a company that partially 
sponsored this work. However, the employment did not cause any bias in relation to the study.

\section{Author details}

${ }^{1}$ School of Agricultural and Veterinarian Sciences, São Paulo State University (UNESP), Jaboticabal, SP, Brazil. ${ }^{2}$ COMIGO - Cooperativa Agroindustrial dos Produtores Rurais do Sudoeste Goiano, Rio Verde, GO, Brazil. ${ }^{3}$ Ceva Saúde Animal, Paulínia, SP, Brazil.

Received: 1 February 2019 Accepted: 30 September 2019

Published online: 14 October 2019

\section{References}

1. Merialdi G, Dottori M, Bonilauri P, Luppi A, Gozio S, Pozzi P, Martelli P. Survey of pleuritis and pulmonary lesions in pigs at abattoir with a focus on the extent of the condition and herd risk factors. The Vet J. 2012;193:234-9.

2. Fraile $L$, Alegre A, López-Jiménez R, Nofrarías M, Segalés J. Risk factors associated with pleuritis and cranio-ventral pulmonary mycoplasma-like lung in slaughter-aged pigs. The Vet J. 2010;184:326-33.

3. Rech RR, Gava D, Silva MC, Fernandes LT, Haach V, Ciacci-Zanella JR, Schaefer R. Porcine respiratory disease complex after the introduction of H1N1/2009 influenza virus in Brazil. Zoonoses Public HIth. 2018;65:e155-61.

4. Morés MA, Oliveira Filho JX, Rebelatto R, Klein CS, Barcellos DE, Coldebella A, Morés N. Aspectos patológicos e microbiológicos das doenças respiratórias em suínos de terminação no Brasil. Pesq Vet Bras. 2015:35:725-33.

5. Takeuti KL, Watanabe TTN, De Castro LA, Driemeier D, Barcellos DESN. Caracterização histopatológica e imuno-hstoquímica da pneumonia causada pela co-infecção por Pasteurella multocida e Mycoplasma hyopneumoniae em suínos. Acta Sci Vet. 2013;41:1117.

6. Fablet C, Marois C, Dorenlor V, Eono F, Eveno E, Jolly JP, Le Devendec L, Kobisch M, Madec F, Rose N. Bacterial pathogens associated with lung lesions in slaughter pigs from 125 herds. Res Vet Sci. 2012;93:627-30.

7. Morés MAZ. Anatomopatologia e bacteriologia de lesões pulmonares responsáveis por condenações de carcaças em suínos. Dissertação (Mestrado em Ciências Veterinárias/Patologia Veterinária) - Universidade Federal do Paraná, Curitiba, 2006; 91.

8. Harbers AHM, Snijders JMA, Smeets JFM, Blocks GHM, van Logtestijn JG. Use of information from pig finishing herds for meat inspection purposes. Vet Quart. 1992;14:41-5.

9. Noordhuizeen JPM, Frankena K, Thrusfield MV, Graat EAM, et al. Application of quantitative methods in veterinary epidemiology. Wageningen Pers. 1997;50.

10. Ciacci-Zanella JR, Schaefer R, Gava D, Haach V, Cantao ME, Coldebella A. Influenza a virus infection in Brazilian swine herds following the introduction of pandemic 2009 H1N1. Vet Microbiol. 2015. https://doi.org/ 10.1016/j.vetmic.2015.08.021.

11. Dalla Costa OA, Morés N, Sobestiansky J, Barioni Junior W, Piffer IA, de Paiva $\mathrm{DP}$, Perdomo C. Fatores de risco associados à rinite atrófica progressiva e pneumonias crônicas nas fases de crescimento e terminação. Embrapa. 2000;267:5.

12. Giacomini E, Ferrari N, Pitozzi A, Remistani M, Giardiello D, Maes D, Alborali GL. Dynamics of Mycoplasma hyopneumoniae seroconversion and infection in pigs in the three main production systems. Vet Res Com. 2016. https:// doi.org/10.1007/s11259-016-9657-6.

13. IDEXX. APP-Apx IV Ab test validation report: IDEXX Laboratories Inc; 2011.

14. Teste IDEXX para Influenza A ab, IDEXX Laboratories Inc, 2010

15. Mycoplasma hyopneumoniae Antibody test kit Validation Data Report, IDEXX Laboratories Inc, 2008.

16. Piffer IA, Brito JRF. Descrição de um modelo para avaliação e quantificação de lesões pulmonares em suínos e formulação de um índice para classificação de rebanhos. Embrapa. 1991:1-11.

17. Davies PR, Bahnson PB, Grass JJ, Marsh WE, Dial GD. Comparison of methods for measurement of enzootic pneumonia lesions in pigs. Am J Vet Res. 1995;56:9-14.

18. Core Team R. R: a language and environment for statistical computing. In: R Foundation for statistical computing. Vienna: Austria. URL; 2018. https:// www.R-project.org/.

19. Meyns T, Dewulf J, Kruif A, Calus D, Haesebrouck F, Maes D. Comparison of transmission of Mycoplasma hyopneumoniae in vaccinated and nonvaccinated populations. Vaccine. 2006;49-50:7081-6.
20. Kich JD, Pontes AP. Análise atual das doenças respiratórias no Brasil. In: Congresso Brasileiro De Veterinários Especialistas Em Suínos. Porto Alegre. Resumos. Porto Alegre: Associação Brasileira de Veterinários Especialistas em Suínos. 2001:58-67.

21. Moreno AM, Barbarini Junior O, Baccaro MR. Levantamento sorológico para Actinobacillus pleuropneumoniae em criações de suínos no período de dezembro de 1996 a julho de 1999. In: Congresso Brasileiro De Veterinários Especialistas Em Suínos. Porto Alegre, RS. Anais. Porto Alegre: Associação Brasileira de Veterinários Especialistas em Suínos 1999;159-160.

22. Stärk KDC. Epidemiological investigation of the influence of environmental risk factors on respiratory diseases in swine-a literature review. The Vet J. 2000;159:37-56.

23. Jäger HC, McKinley TJ, Wood JL, Pearce GP, Williamson S, Strugnell B, Done S, Habernoll H, Palzer A, Tucker AW. Factors associated with pleurisy in pigs: a case-control analysis of slaughter pig data for England and Wales. PLoS One. 2012;7:2

24. Sibila M, Calsamiglia M, Vidal D, Badiella L, Aldaz A, Jensen JC. Dynamics of M. hyopneumoniae infection in 12 herds with different production systems. Can J Vet Res. 2004;68:12-8.

25. Sibila M, Pieters M, Molitor T, Maes D, Haesebrouck F, Segales J. Current perspectives on the diagnosis and epidemiology of Mycoplasma hyopneumoniae infection. The Vet J. 2009;181:221-31.

26. Janke BH. Influenza A virus infections in swine: pathogenesis and diagnosis. Vet Pathol. 2014;51:410-26.

27. Tobias TJ, Bouma A, Van Den Broek J, Van Nes A, Daemen AJJM, Wagenaar JA, Klinkenberg D. Transmission of Actinobacillus pleuropneumoniae among weaned piglets on endemically infected herds. Prev Vet Med. 2014;117:207-14.

28. Byrt D, Heap P, Pointon AM. Effect of enzootic pneumonia of pigs on growth performance. Aus Vet J. 1985;62:13-8.

29. Ferrari CV. Efeito do peso ao nascer e ingestão de colostro na mortalidade e desempenho de leitões após a uniformização em fêmeas de diferentes ordens de parição. Dissertação de mestrado. Programa de Pós-graduação em Ciências Veterinárias. Porto Alegre. 2013:53.

\section{Publisher's Note}

Springer Nature remains neutral with regard to jurisdictional claims in published maps and institutional affiliations.

Ready to submit your research? Choose BMC and benefit from

- fast, convenient online submission

- thorough peer review by experienced researchers in your field

- rapid publication on acceptance

- support for research data, including large and complex data types

- gold Open Access which fosters wider collaboration and increased citations

- maximum visibility for your research: over $100 \mathrm{M}$ website views per year

At BMC, research is always in progress.

Learn more biomedcentral.com/submissions 